\title{
Why is cyanide acutely lethal at very low doses?
}

\author{
Kelath Murali Manoj* \\ *Satyamjayatu: The Science \& Ethics Foundation \\ Kulappully, Shoranur-2 (PO), Palakkad District, Kerala State, India-679122. \\ satyamjayatu@yahoo.com
}

\begin{abstract}
Cyanide is conventionally perceived as a binder of heme-Fe centers, disrupting oxygen transport by blood hemoglobin and mitochondrial cytochrome oxidase function. This explanation of toxicity would require millimolar ( $\mathrm{g} / \mathrm{Kg}$ dosage) concentration of cyanide, whereas it is lethal even at micromolar (mg/Kg dosage) ranges. It is long known that oxygen consumption by cells leads to the production of diffusible reactive oxygen species (DROS). Recently, DROS mediated catalytic/metabolic roles were proposed as a physiological source of heat and phosphorylation of ADP within mitochondria. In this purview, it is hypothesized herein that cyanide uses the catalytic DROS via futile cycles, stopping ATP-synthesis and thus killing cells. A quantitative mechanistic perspective delineating the old and new explanations is provided herein. Further, experimental modalities and predictable outcomes are detailed to test the new hypothesis.
\end{abstract}

Keywords: cyanide-poisoning, murburn concept, cellular respiration, ATP-synthesis, hemoglobin, cytochrome oxidase, mitochondria, reactive oxygen species (ROS). 


\section{Introduction}

Cyanide caught human attention dates three centuries back, with the synthesis/discovery of the dye Prussian blue (ferric ferrocyanide, $\mathrm{Fe}_{7}[\mathrm{CN}]_{18}$ ) and prussic acid (hydrogen cyanide, $\mathrm{HCN}$ ). Owing to its lethality, cyanide salts and acid (hereon termed $\mathrm{CN}$ ) have been regulated by governments. Therefore, it has captured the imagination of common-folk and erudite alike, across cultures and continents. Though $\mathrm{CN}$-based lethality is well studied, the exact reason for cell/organism mortality is not yet nailed. The traditional view for explaining $\mathrm{CN}$-toxicity entails a binding-based mechanism wherein important hemeFe centers are blocked by a highly efficient cyanide ligation. ${ }^{1-2}$ Recently, an oxygen-centric mechanism called murburn (abstracted from 'mured burning') concept was proposed to explain for the physiology of xenobiotic metabolism and cellular respiration. ${ }^{3-7}$ The new proposal states that diffusible reactive oxygen species (DROS) generated at the mitochondrial complexes directly serve as the coupling agents of oxidative phosphorylation. Within this purview, it is hypothesized herein that cyanide (radical) subjects the DROS generated in milieu into futile cycles, disrupting the energy requisites for life. Therefore, cyanide toxicity can be seen under two mechanistic considerations, as shown in Figure 1.

Figure 1. A scheme of the two mechanistic explanations for the toxicity of cyanide: In the textbook explanation, $C N$ ligates to heme-center, thereby preventing oxygen's accessibility, transport or reduction thereafter. This is a 1:1 reaction outcome, resulting out of a physical binding. In the new hypothesis, cyanide (radical) reacts with the catalytic DROS generated/stabilized at heme-center, thereby disrupting ATP-synthesis. This is a mechanism wherein cyanide acts as a recyclable catalyst.
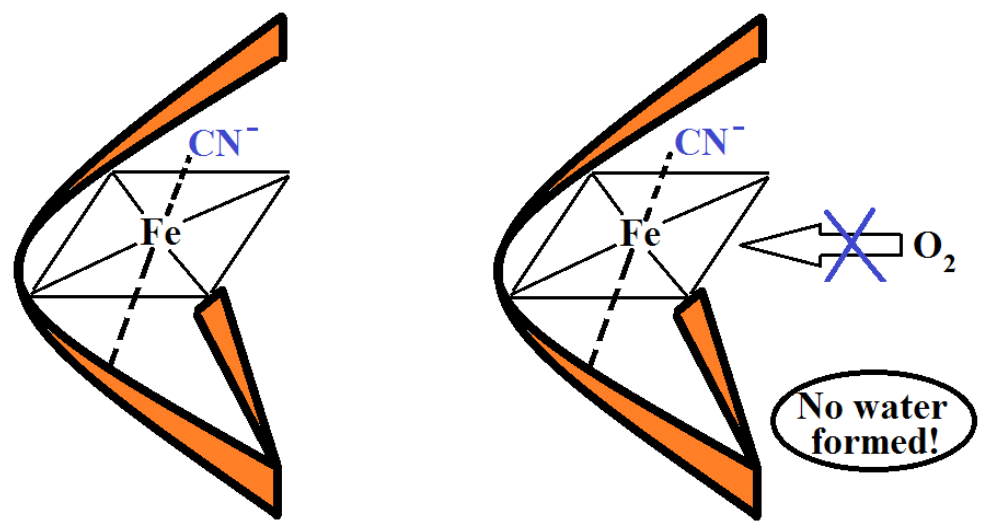

\section{Cyanide-binding based explanation}

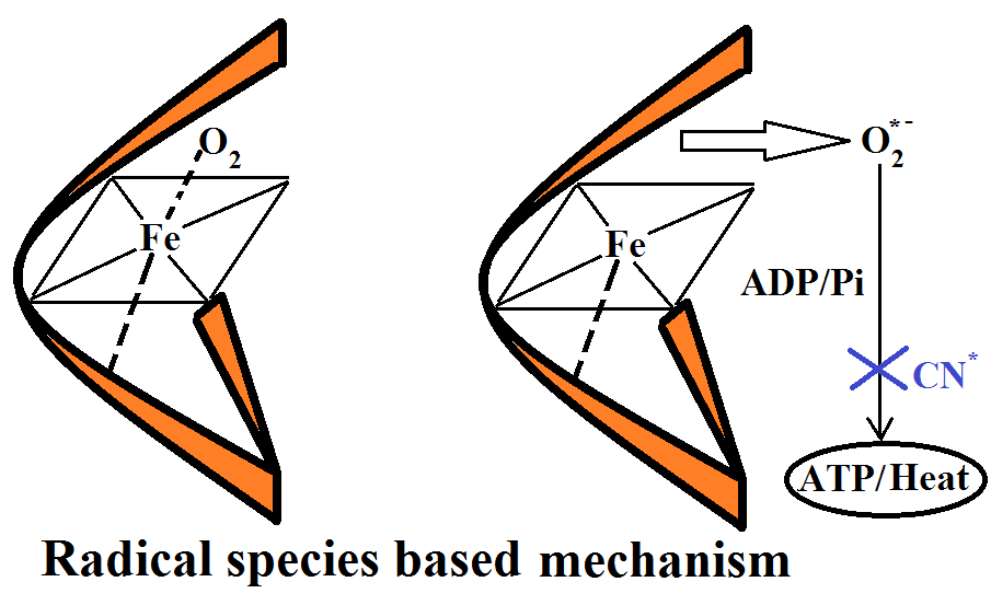




\section{Critical assessment of the old explanation:}

A. Assessment of cyanide's toxicity based on blood's oxygen transporting capacity: Each RBC contains $\sim 10^{9} \mathrm{CN}$-binding sites $\left(=2.5 \times 10^{8}\right.$ hemoglobin, $\mathrm{Hb} \times 4$ sites per $\left.\mathrm{Hb}\right)$ and since one liter of blood contains $5 \times 10^{12}$ RBC, 5 liters of blood in a human has $\sim 2.5 \times 10^{22}$ binding sites of CN. As blood levels of $\sim 3 \mathrm{mg} / \mathrm{L}$ cyanide is accepted to be lethal, the threshold blood load is $15 \mathrm{mg}$ of cyanide. ${ }^{8}$ Since $26 \mathrm{~g}$ (ionic mass) of cyanide contains $6.023 \times 10^{23}$ cyanide ions, $15 \mathrm{mg}$ contains $\left[\left(6.023 \times 10^{23}\right) \times(15 / 26) / 1000\right]=3.5 \times 10^{20}$ cyanide ions. Granting the best-case scenario of $100 \%$ irreversible binding efficiency, the CN lethal load is only a minute fraction of the total binding sites in blood. This leads to the inference that cyanidelethality is not brought about by disruption of $\mathrm{Hb}-\mathrm{O}_{2}$ transport.

B. A statistical analysis of $\mathrm{CN}$-binding to the heme-center of Complex IV: An average human has $>10^{13}$ cells. Considering $\sim 10^{7}$ Complex IV per cell $\left(=10^{4}\right.$ Complex IV per mitochondrion $x \sim 10^{3}$ mitochondria per cell), ${ }^{9}$ the estimate for the total Complex IV binding sites is $\sim 10^{20}$. Across several organisms/animals (including humans), $\mathrm{KCN}$ is lethal when administered (orally) at $\sim 1 \mathrm{mg} / \mathrm{Kg}$. ${ }^{10}$ Assuming complete absorption and equi-distribution within a body mass (with equal density as water), the toxic physiological concentration of $\mathrm{CN}$ comes to $\leq 10^{-6} \mathrm{M}(\mathrm{mg} / \mathrm{Kg}$ or $\mathrm{mg} / \mathrm{L})$. In vivo or in situ, the actual and effective concentration of $\mathrm{CN}$ would be far lower than what is administered, owing to loss through nonabsorption (in the gut) and metabolism/excretion (by say, kidneys). This means that the $10^{20} \mathrm{CN}$ present in the $\mathrm{mg} / \mathrm{Kg}$ administration (calculated in point $\mathrm{A}$ above) would not be adequate for lethality even if the binding to Complex IV was $100 \%$ irreversible and efficient.

However, quite unlike $\mathrm{CO}$ binding, cyanide-binding to heme-centers is neither irreversible nor efficient in physiological realms. ${ }^{11}$ The thermodynamic equilibrium dissociation constant $K_{d}$ is defined as the concentration of $\mathrm{CN}$ at which half of the total available heme-centers is populated by the ligand (CN). Usually, when micromolar levels of protein is taken, at least $10 \mathrm{X} \mathrm{K}_{d}$ concentration of ligand is minimally required to get $>90 \%$ of the total active sites occupied. Even in such conditions, binding is via a noncovalent but coordination scheme of 'off-now, on-now' kind of interaction, and it is not an 'always bound' scenario. ${ }^{11}$ As measured by non-invasive spectroscopic assays in pure solutions, cyanide binding to micromolar levels of hemeproteins show $K_{d}$ values $\sim 10^{-3} M^{12,13}$ In particular, the affinity-based $K_{d}$ of cyanide for Complex IV is $\sim 1 \mathrm{mM}$ ranges (quite similar to that of oxygen) and cyanide has relatively low affinities both for the oxidized and reduced forms of Complex IV. ${ }^{14}$ This reality translates to a requirement of $\mathrm{g} / \mathrm{Kg}$ or $\mathrm{g} / \mathrm{L}$ dosage administration for achieving binding-based lethality (as calculated in point $B$ above). Further, binding of small species to membrane-bound proteins with deep-seated active sites would be relatively slow, owing to constraints imposed by diffusion. ${ }^{13}$ Physiologically, the symmetric diatomic oxygen molecule should out-compete the asymmetric triatomic HCN or diatomic cyanide for binding Complex IV because the hydrophobic oxygen is present at several orders higher concentrations $\left(>10^{-4} \mathrm{M}\right)$ in/around the membrane milieu. The ligation of cyanide to heme-Fe finally results via the carbon atom of the $\mathrm{CN}^{-}$anion. It is known that the $\mathrm{pK}_{\mathrm{a}}$ of $\mathrm{HCN}$ is 9.4, two logarithmic units higher than the physiological $\mathrm{pH}$. Even if an active site amino acid residue can aid HCN binding, this function would be efficient in $\mathrm{pH}$ range closer to the $\mathrm{pK}_{\mathrm{a}}$ of $\mathrm{HCN}$, implying that only a small fraction $\mathrm{CN}$ would effectively bind to Fe-centers at physiological regimes. Further, the rate constant $k_{\text {on }}$ for cyanide interaction with hemeprotein, falls in the range of only $10^{2}$ to $<10^{4} \mathrm{M}^{-1} \mathrm{~s}^{-1}{ }^{11}$ Such a slow/reversible binding cannot explain the fast/acute cyanide toxicity. Therefore, binding-based calculations fall short of explaining the outcomes by several orders of magnitude. Other traditional explanations that lead to specific organ or tissue failures stem from the molecular mechanisms related to heme-Fe and $\mathrm{CN}$ binding. Therefore, the old hypothesis is untenable for explaining the disruptive efficacy of cyanide. 
Arguments favoring the new hypothesis:

In our recent works with (sub)micromolar levels of heme-enzymes and several toxic small molecules and ions ( $\mathrm{N}$-heterocyclics, cyanide/azide, etc.), we had shown that the latter are more likely to act as pseudo-substrates in milieu. ${ }^{12,13,15,16}$ This implies that only at higher heme:ligand ratios and high enzyme concentrations, an ion like cyanide serves as an efficient active-site ligand. The in situ or in vitro assays show a functional $I C_{50}$ or pseudo- $K_{i}$ or pseudo- $K_{M}$ of $\sim 10^{-6} \mathrm{M}$ for certain cyanide-enzyme reactions, $12,13,15,16$ which captures the essence of physiological inhibitions. We have also provided several evidence based arguments that DROS generated in milieu are obligatorily required for ATP-synthesis, heat generation, and other redox metabolic routines. ${ }^{3-7}$ Further, DROS-radical reactions are fast, with rate constant $k$ values of $10^{8}$ to $10^{9} \mathrm{M}^{-1} \mathrm{~s}^{-1}$, (six orders higher than the heme-binding rates!) which could potentially explain the rapid/acute toxicity of cyanide (radical). Therefore, under physiological scenarios, the role of cyanide is given by the criteria in Box 1.

Box 1: Reaction-based inhibitory roles of cyanide in physiological milieu.

\begin{tabular}{|c|c|}
\hline $\begin{array}{l}\text { At low levels, } \mathrm{HCN} \\
\text { acts as a catalyst, } \\
\text { dissipating DROS } \\
\text { via futile cycles. }\end{array}$ & $\begin{array}{l}\text { At higher levels, } \mathrm{HCN} \text { reacts to } \\
\text { give cyanate, also setting in a } \\
\text { pseudo-chain reaction, raising } \\
\text { pH and enabling } C N \text {-binding. }\end{array}$ \\
\hline $\begin{array}{c}\mathrm{HCN}+\mathrm{OH}^{*} \rightarrow \mathrm{CN}^{*}+\mathrm{H}_{2} \mathrm{O} \\
\mathrm{CN}^{*}+\mathrm{O}_{2}{ }^{*-} \rightarrow \mathrm{CN}^{-}+\mathrm{O}_{2}\end{array}$ & $\begin{aligned} \mathrm{HCN}+\mathrm{O}_{2}{ }^{*} & \rightarrow \mathrm{CN}^{*}+\mathrm{HO}_{2}^{-} \\
2 \mathrm{HCN}+2 \mathrm{OH}^{*} \rightarrow & 2 \mathrm{CN}^{*}+2 \mathrm{OH}^{-}+2 \mathrm{H}^{+} \\
2 \mathrm{CN}^{*} & \rightarrow(\mathrm{CN})_{2} \\
(\mathrm{CN})_{2}+2 \mathrm{OH}^{-}+2 \mathrm{H}^{+} & \rightarrow \mathrm{HCNO}+\mathrm{HCN}+\mathrm{H}_{2} \mathrm{O}\end{aligned}$ \\
\hline $\mathrm{OH}^{*}+\mathrm{O}_{2}^{*} \rightarrow \mathrm{H}_{2} \mathrm{O}+\mathrm{O}_{2}$ & $2 \mathrm{HCN}+\mathrm{O}_{2}{ }^{*}+2 \mathrm{OH}^{*} \rightarrow \mathrm{CNO}^{-}+\mathrm{CN}^{*}+\mathrm{H}_{2} \mathrm{O}+\mathrm{H}_{2} \mathrm{O}_{2}$ \\
\hline
\end{tabular}

So, cyanide can effectively inhibit DROS utilization, forming non-productive two-electron sinks (peroxide or water). In short, within the old binding-based purview, cyanide is a SUICIDE INHIBITOR, getting consumed in the process. In the new murburn explanation, cyanide (radical) can effectively serve as a CATALYTIC INHIBITOR, which does not get consumed. At low levels $\left(\leq 10^{-6} \mathrm{M}\right)$, via fast reactions occurring in the matrix, cyanide anion-cyanide radical equilibrium effectively dissipates the functional DROS. With latency and at higher cyanide levels, clinical cyanosis could result. This is due to the production of the basic cyanate ion, which increases $\mathrm{pH}$, enabling cyanide ion ligation to heme-Fe. Therefore, death and cyanosis owes more to the production of cyanide radical and not owing to the original binding affinity of cyanide ion or HCN, per se. In heme-enzyme systems, EPR spectroscopy has evidenced the presence of cyanide radicals and the formation of cyanate (from cyanide) has also been reported. $^{17,18}$

Predictability and verifiability of the hypotheses: 
* In respiring cells or mitochondrial suspension, the catalytic role of cyanide radical/DROS can be traced by the incorporation of radio-labeled carbon in cyanide or radio-labeled oxygen. After exposing an experimental system to the molecular probes, the radio-labeled cyanate formation can be traced to confirm the radical pathway of $\mathrm{CN} /$ oxygen interaction. On the other hand, if $\mathrm{CN}$ binding to heme is efficient and irreversible, cyanate should not be formed.

* Per the erstwhile purview, since cyanide has no bearing with Complexes I, II, III \& V, these proteins should produce ATP via the "proton-based machinery", if the old mechanisms were operative. So, at $\mathrm{K}_{\mathrm{d}}$ (mM) concentrations of cyanide taken experimentally, only $50 \%$ of Complex IV is 'bound by cyanide'. That would still leave 1:1-2:2-3:2-3:4-6:5-9 ratio of the complexes (I:II:III:IV:V:Cyt.c) in the mitochondrial suspension, and only a minimal or stoichiometric loss of activity should be noted. ${ }^{5,9}$ The new scheme predicts an overwhelming loss (practical cessation) in the ATP production ability of the system.

* A 'cyanide-blocked' system could be subjected to a favorable external pH gradient (say, 6.5 out to 9.5 in), quite similar to the demonstration by Mitchell's group or a rhodopsin assisted ATP-synthesis via Racker-Stoeckinius type setups. ${ }^{19,20}$ While the erstwhile hypothesis does not seek inhibitions, the new perspective advocates cessation of fresh ATP synthesis.

\section{Conclusion}

Quite analogous to the in situ and physiological dose responses mediated by low concentrations of toxic agents (that form radicals), ${ }^{13,15,16}$ it is proposed acute lethality of cyanide results due to radical chemistry. Verifications of the hypothesis may aid cyanide-poisoning therapy in the future and also potentially qualify research efforts in redox medicine.

Acknowledgments: This work was powered by Satyamjayatu: The Science \& Ethics Foundation. KMM thanks Alexander Scheeline (UIUC, USA) and Vivian David Jacob (Bioculer, Kottayam) for inputs.

\section{References}

1. Beasley DMG, Glass WI. Cyanide poisoning: pathophysiology and treatment recommendations. Occup Med 1998; 48:427-431. doi:10.1093/occmed/48.7.427

2. Alberts B, Johnson A, Lewis J, Raff M, Roberts K, Walter P (1994). Molecular Biology of the Cell. New York: Garland Publishing Inc. ISBN 978-0-8153-3218-3

3. Parashar A, Gade SK, Potnuru M, Madhavan N, Manoj KM. The curious case of benzbromarone: insight into super-inhibition of cytochrome P450. PLoS One 2014; 9:e89967. doi:10.1371/journal.pone.0089967

4. Manoj KM, Parashar A, Gade SK, Venkatachalam A. Functioning of microsomal cytochrome P450s: Murburn concept explains the metabolism of xenobiotics in hepatocytes. Front Pharmacol 2016; 7:161. doi:10.3389/fphar.2016.00161

5. Manoj KM. Debunking chemiosmosis and proposing murburn concept as the explanation for cellular respiration. Biomed Rev 2017; 28:35-52. doi:10.14748/bmr.v28.4450

6. Manoj KM, Parashar A, Jacob VD, Ramasamy S. Aerobic Respiration: Proof of concept for the murburn perspective. J Biomol Str Dynam 2019. doi: 10.1080/07391102.2018.1552896.

7. Manoj KM, Gideon DA, Jacob VD. Murburn scheme for mitochondrial thermogenesis. Accepted in Biomed Rev 2018; 29. (preprint- arXiv:1812.06089 [q-bio.SC] 2018) 
8. Anseeuw K, Delvau N, Burillo-Putze G, De laco F, Geldner G, Holmström P. Lambert Y, Sabbe M. Cyanide poisoning by fire smoke inhalation: a European expert consensus. Eur J Emerg Med 2013; 20: 2-9. doi:10.1097/mej.0b013e328357170b

9. Schwerzmann K, Cruz-Orive LM, Eggman R, Sänger A, Weibel ER. Molecular architecture of the inner membrane of mitochondria from rat liver: a combined biochemical and stereological study. J Cell Biol 1986; 102:97-103. doi:10.1083/jcb.102.1.97

10. Taylor J, Roney N, Harper C, Fransen ME, Swarts S. Toxicological profile for cyanide. Agency for Toxic Substances and Disease Registry 2006. (https://www.atsdr.cdc.gov/toxprofiles/tp8.pdf)

11. Cooper CE, Brown GC. The inhibition of mitochondrial cytochrome oxidase by the gases carbon monoxide, nitric oxide, hydrogen cyanide and hydrogen sulfide: chemical mechanism and physiological significance. J Bioenerg Biomembr 2008; 40:533-539. doi:10.1007/s10863-0089166-6

12. Parashar A, Venkatachalam A, Gideon DA, Manoj KM. Cyanide does more to inhibit heme enzymes, than merely serving as an active-site ligand. Biochem Biophys Res Commun 2014; 455:190-193. doi:10.1016/j.bbrc.2014.10.137

13. Manoj KM, Parashar A, Avanthika V, Goyal S, Moharana S, Singh PG, et al. Atypical profiles and modulations of heme-enzymes catalyzed outcomes by low amounts of diverse additives suggest diffusible radicals' obligatory involvement in such redox reactions. Biochimie 2016; 125:91-111. doi:10.1016/j.biochi.2016.03.003

14. Antonini E, Brunori M, Greenwood C, Malmstrom BG, Rotilio GC. The interaction of cyanide with cytochrome oxidase. Eur J Biochem 1971; 23:396-400. doi:10.1111/j.1432-1033.1971.tb01633.x

15. Andrew D, Hager L, Manoj KM. The intriguing enhancement of chloroperoxidase mediated oneelectron oxidations by azide, a known active-site ligand. Biochem Biophys Res Commun 2011; 414:646-649. doi:10.1016/j.bbrc.2011.10.128

16. Parashar A, Gideon DA, Manoj KM. Murburn concept: A molecular explanation for hormetic and idiosyncratic dose responses. Dose Response 2018; 16:1559325818774421. doi:10.1177/1559325818774421

17. Moreno SNJ, Stolze K, Janzen EG, Mason RP. Oxidation of cyanide to the cyanyl radical by peroxidase $/ \mathrm{H}_{2} \mathrm{O}_{2}$ systems as determined by spin trapping. Arch Biochem Biophys 1988; 265:267271. doi:10.1016/0003-9861(88)90127-0

18. Delporte C, Zouaoui Boudjeltia K, Furtmuller PG, Maki RA, Dieu M, Noyon C, et al. Myeloperoxidase-catalyzed oxidation of cyanide to cyanate: A potential carbamylation route involved in the formation of atherosclerotic plaques? J Biol Chem 2018; 293:6374-6386. doi:10.1074/jbc.M117.801076

19. Reid R, Moyle J, Mitchell P. Synthesis of adenosine triphosphate by a protonmotive force in rat liver mitochondria. Nature 1966; 212:257-258.

20. Racker $E$, Stoeckenius $W$. Reconstitution of purple membrane vesicles catalyzing light-driven proton uptake and adenosine triphosphate formation. J Biol Chem 1974; 249:662-663. 